\title{
PESSOA/BERNARDO SOARES E HEIDEGGER: POESIA E PENSAMENTO CONTRA A DECADÊNCIA
}

Cláudia Grijó Vilarouca ${ }^{1}$

RESUMO: Fernando Pessoa e Heidegger compartilham um sentimento comum de pertencerem a uma época de decadência. Isso pode ser constatado na poesia de Pessoa e na filosofia de Heidegger. No entanto, suas obras não são simplesmente um reflexo dessa época, elas são uma resposta a um chamado: a fundação do Ser pela poesia e pelo pensamento. Em Pessoa, esse chamado o leva mais longe: ele propõe a constituição de uma nova alma portuguesa.

PALAVRAS-CHAVE: Fernando Pessoa; Heidegger; decadência; poesia; Ser;

RÉSUMÉ: Fernando Pessoa et Heidegger éprouvent un sentiment commun d'appartenance à une époque de décadence. Cela peut être constaté dans la poésie de Pessoa et dans la philosophie de Heidegger. Cependant, leur œuvre n' est pas tout simplement un reflet de cette époque, c'est la réponse à un appel : la fondation de l'Être par la poésie et la pensée. Chez Pessoa, cet appel le conduit plus loin : il propose la constitution d'un nouvel esprit portugais.

MOTS-CLÉS : Fernando Pessoa; Heidegger; décadence; poésie; Être;

Heidegger considerava a época em que vivia decadente, eram tempos de indigência, resultado, em parte, do desenvolvimento desmedido da técnica que transformou o mundo em objeto, tendo ocasionado um desenraizamento do homem. Ele nos diz ainda que

\begin{abstract}
A perda do enraizamento não é provocada somente por circunstâncias externas e fatalidades do destino, nem é o efeito da negligência e do modo de vida superficial dos Homens. A perda do enraizamento provém do espírito da época, no qual todos nós nascemos. (HEIDEGGER, 2000, p. 17).
\end{abstract}

\footnotetext{
${ }^{1}$ Doutoranda do Programa de Pós-Graduação em Literatura da Universidade Federal de Santa Catarina.
} 
Fernando Pessoa possui um parecer muito próximo ao de Heidegger, que era seu coetâneo, claramente constatado na prosa poética de Bernardo Soares: "Quando nasceu a geração a que pertenço encontrou o mundo desprovido de apoios para quem tivesse cérebro, e ao mesmo tempo coração." Termina este fragmento exprobrando: O direito a viver e a triunfar conquista-se hoje quase pelos mesmos processos por que se conquista o internamento num manicômio: a incapacidade de pensar, a amoralidade e a hiperexcitação" (PESSOA, 1999, p. 188). Essa atmosfera de decadência, na qual vive Pessoa, se faz conhecer em sua poesia que "deve ser vist[a] como uma imensa reinvenção das sobras do dia-a-dia, como se de um lado ficasse a matéria deteriorada e, de outro, o fluxo de uma sublime depuração" (OSAKABE, 2002, p. 31). A reinvenção das sobras cotidianas se realiza pela faculdade de pensar.

O filósofo alemão aponta justamente para o pensamento como uma possível saída para esse tempo decadente e podemos dizer que Pessoa trilha uma via semelhante, paralela a de Heidegger, porém pela poesia. Para Heidegger não se trata de qualquer pensamento, mas sim de um "pensamento que medita". Isso evitaria que ficássemos atrelados a um só tipo de representação, que nos lançássemos a ela como a única possível (HEIDEGGER, 2000, p. 23). O filósofo alemão alude à objetificação do mundo tal como a técnica "solicita". A técnica não pode mais ser contida no sentido de não se poder mais voltar no tempo para estagnar seu processo de evolução histórica, todavia ela pode ser refreada se não nos deixarmos absorver. Com o domínio da técnica, Heidegger nos adverte que há um perigo à espreita e o Homem corre o risco de perder sua essência, "aquilo que tem de mais próprio, ou seja, o facto de ser um ser que reflecte" (HEIDEGGER, 2000, p. 26). Caso isso ocorra, tornamo-nos não mais humanos, mas autômatos, tudo está em nós e não há espaço para o pensamento. Pessoa percebeu esse fato:

(...) cada um de nós nasceu doente de toda esta complexidade. Em cada alma giram os volantes de todas as fábricas do mundo, em cada alma passam todos os comboios do globo, todas as grandes avenidas de todas as grandes acabam em cada uma das nossas almas. Todas as questões sociais, todas as perturbações políticas, por pouco que com elas nos preocupemos, entram no nosso organismo psíquico, no ar que respiramos psiquicamente, passam para o nosso sangue espiritual, passam a ser, inquietantemente, nossas como qualquer cousa que seja nossa. (PESSOA, 1974, p. 437). 
Há uma grande quantidade de estímulos que aumentam gradativamente com o progresso da técnica, a ponto de passarem "para o nosso sangue espiritual”. Há nisso um alheamento do próprio mundo vivido, do Ser, ao mesmo tempo em que somos devorados pelos produtos que nós mesmos produzimos. Bernardo Soares, ao retratar esse tempo, reclama de como ficamos "alheios à solenidade de todos os mundos, indiferentes ao divino e desprezadores do humano"; sendo assim "entregamo-nos futilmente à sensação sem propósito, cultivada num epicurismo subtilizado" (PESSOA, 1999, p. 45).

Somente pela poesia - no sentido heideggeriano - é que se pode preservar o Ser. A poesia demonstra que há uma "região" da vida que a técnica ainda não pode manipular. A técnica não deixa de ser uma oposição à poesia, pois aquela nega aquilo que não pode ser dominado, ela dessacraliza, enquanto que esta última salvaguarda o sagrado (que não concerne à religião).

O sentido mais original de "poesia", ao qual Heidegger irá recorrer para abordar a poesia de Hölderlin", está vinculado ao vocábulo grego poiesis “criação, fabricação, confecção", e ao adjetivo "poético", poietikós "que tem a virtude de fazer, de criar, de produzir, próprio para fabricar, inventivo".

A essência da poesia consiste então em ser ela uma linguagem fundante. "Le dire du poète est fondation (...) en ce sens qu'il assied et assure sur sa base l'être-là de l'homme"3 (HEIDEGGER, 1973, p. 53). Sendo fundante, a poesia é um dos meios onde a verdade do ser acontece. Ela é também espanto, pois restaura algo perdido das coisas, seu Ser. No fazer poético reside uma missão, o que não implica dizer que o poeta tenha consciência dela. Todavia, Pessoa parecia sim saber do papel de sua poesia quando diz:

a consciência (que em mim é quotidiana) da terrível importância da Vida, essa consciência que nos impossibilita de fazer arte meramente pela arte, e sem a consciência de um dever a cumprir para com nós próprios e para com a humanidade. (PESSOA, 1974, p. 53).

\footnotetext{
${ }^{2}$ Heidegger possui um curso chamado "Hinos de Hölderlin", em que ele interpreta, grosso modo, a poesia de Hölderlin como uma profecia do advento de novos tempos para o povo alemão.

3 “ o dizer do poeta é fundação (...), no sentido que ele assenta e assegura sobre sua base o ser-aí do homem." (trad. minha)
} 
A poesia que ele produziu oferece diferentes modos de sentir. Cada persona pessoana carrega consigo um matiz diferente de realidade. A poesia tem esse caráter de tratar de coisas que nos circundam desvelando-as. Pedras são pedras; o vento é frio, ou é agradável, ou é quente; a luz do sol é forte ou fraca; a árvore está ali - essa é a atitude cotidiana que a poesia dilacera para dar voz às coisas do mundo. Afinal "las piedras dicen algo, el viento dice, la ventana iluminada y el árbol solo de la esquina dicen, todo está diciendo algo, no esto que digo sino otra cosa, siempre otra cosa, la misma cosa que nunca se dice" (PAZ, 1983, pp.127-8). Logo, a função do poeta é pôr o mundo em aberto e nos fazer adentrar na esfera de potência da poesia. É preciso pensar na "vocation spéculative de la littérature, en soutenant qu'elle a authentiquement valeur d'une expérience de pensée" ${ }^{5}$ (MACHEREY, 1990, p. 10), pois ela nos convida à reflexão assim como o próprio discurso filosófico o faz, cada qual a sua maneira.

A linguagem instaura o mundo. Porém, a fundação da verdade do ser, no sentido que Heidegger dá à verdade, que é desocultação, não ocorre em qualquer linguagem, como por exemplo na cotidiana, mas na da poesia e na do pensador, na medida em que as linguagens destes últimos são poiesis, são o tipo de linguagem que estruturam o sentido. Em Bernardo Soares, encontramos uma prosa poética, como ele mesmo diz, cuja expressão alça vôo e nos revela poeticamente fragmentos de mundo.

Se enfatizo Bernardo Soares neste artigo, é porque o considero a expressão máxima pessoana, na qual ecoa Caeiro, Campos, Reis e versos do próprio Pessoa. Como bem atesta Leyla Perrone-Moisés: “dizer, para ele [B. Soares], não é representar o mundo nem expressar o homem; é criá-los, fazê-los existir: 'Toda a literatura consiste num esforço para tornar a vida real'”(PERRONE-MOISÉS, 2001, p. 272).

De certo modo, F. Pessoa dá indício a elaboração de uma arte com o intuito de fazer despertar uma percepção ou uma perspectiva múltipla do mundo - um modo de viajar sem sair do lugar, afinal, pois "a melhor maneira de viajar é sentir", como diz Álvaro de Campos - enfim, para produzir vida, de acordo com José Gil em Fernando

\footnotetext{
4 “as pedras dizem algo, o vento diz, a janela iluminada, a árvore solitária da esquina dizem, tudo está dizendo algo, não isso que digo, mas outra coisa, sempre outra coisa, a mesma coisa que não se diz nunca." (trad. minha)

5 "a vocação especulativa da literatura, sustentando que ela tenha autenticamente valor de uma experiência de pensamento". (trad. minha)
} 
Pessoa ou a Metafísica das sensações. Pessoa cria que "a variedade alargará o espírito". (PESSOA, 1974, p. 267).

Ao apresentar uma proposta poética heteronímica, seus vários “eus”, Pessoa revela ter consciência da pluralidade e resolve adotá-la. Tal multiplicidade do sentir engendra novas cosmovisões, expressadas pelos heterônimos. Entretanto, a meu ver, não se trata apenas de um fazer poético plural, um projeto individual. Pessoa visava à formação de uma nova alma portuguesa. O sentimento decadentista, exposto no início deste trabalho, refere-se também à pátria, como podemos entrever nesse trecho:

\begin{abstract}
Não há outro problema hoje de mais importância do que criar uma alma portuguesa. A antiga alma nacional, mesmo que ainda existisse, já não servia. É preciso, para que haja um Portugal Novo, haver uma Nova Alma Portuguesa. Para que possa haver uma política nacional, uma cultura nacional, qualquer coisa nacional, seja o que for, o primeiro passo a dar é espiritual, é criar aquela fonte nacional donde essas coisas, todas, depois inevitavelmente partirão. (PESSOA, 1978, p. 35).
\end{abstract}

Pode-se dizer que há um "projeto espiritual" sugerido pelo poeta que se concretizaria na pluralidade - aspirando a uma universalidade (a criação heteronímica é um exemplo). Na verdade, tal projeto está em relação direta com a idéia de destinação de Portugal. É possível, deste modo, vislumbrar um projeto poético de Pessoa para a Pátria.

Pessoa quer suscitar poeticamente a idéia precisa de um Portugal ao mesmo tempo singular (pela retomada de sua história, vangloriando-a) e universal (pelo anúncio de sua capacidade ideal de ser o nome um 'Quinto Império'). (BADIOU, 2002, p. 64).

O poético aqui não se reporta ao lirismo, mas sim, ao acesso para o Ser. Pessoa queria ser um criador de mitos, que para ele, é o mistério mais alto (PESSOA, 1974, p. 84). Em que sentido ele quer criar mito? A investigação que tenho realizado leva-me a crer que esse mito é a instauração da universalidade da Pátria portuguesa. Num trecho de uma carta a Armando Cortes-Rodrigues, Pessoa afirma que "fazer arte parece-me cada vez mais importante coisa, mais terrível missão - dever a cumprir arduamente, monasticamente, sem desviar os olhos do fim criador-de-civilização de toda a obra artística." (PESSOA, 1974, p. 54). 
Se as navegações geraram um mito, o de Portugal enquanto nação predestinada a uma missão de caráter global, Pessoa parecia desejar criar o mito de que a Nação Portuguesa deveria conduzir a humanidade a outra descoberta, mas no plano espiritual:

E a nossa grande Raça partirá em busca de uma Índia nova, que não existe no espaço, em naus que são construídas 'daquilo de que os sonhos são feitos'. E o seu verdadeiro e supremo destino, de que a obra dos navegadores foi o obscuro e carnal ante-arremedo, realizarse-á divinamente. (PESSOA, 1974, p. 397).

Sua poesia conclama à escuta do apelo da terra, e lanço essa hipótese, quanto mais se multiplicar melhor esse apelo pode ser ouvido e entendido. Os heterônimos apontam caminhos para a pluralidade, para realidades heterogêneas, para o cosmopolitismo. Essa escuta vai fazer romper novos horizontes, visto que:

Neste nosso tempo esvaziado de mitos, o indivíduo tem detrás de si, não simplesmente uma herança ou uma tradição cultural que possa aceitar ou rejeitar, mas um espaço vivenciável que o restringe e determina, de tal modo que a trajetória a ser percorrida entre nascimento e morte está já traçada, em suas grandes linhas e direções, antes mesmo que esse indivíduo venha ao mundo. (MOISÉS, 1999, p. 135).

Pessoa quis lutar contra esse determinismo, por isso tentou ensinar que o sonho é a saída para a estagnação do espírito, o sonho implica um devir e, por conseguinte, como já expus, o sonho é que possibilita viver plenamente a vida. Sonhar é poetizar o mundo. Poetizar o mundo é responder um apelo.

Eis a "missão": "a de resgatar o subconsciente nacional não tanto de históricos e acidentais complexos de dependência, mas de si mesmo, transfigurando a gesta particular de um pequeno-grande-povo, em gesta de consciência universal" (LOURENÇO, 1982, p. 115). Logo, o poeta lançou-se à luta contra decadência dos tempos, e também de sua pátria.

Era então necessário fundar a nova alma portuguesa e Pessoa preconiza a arte, sobretudo a literatura/poesia enquanto caminho para tal. A poesia passa a ser a condição de possibilidade para delinear o Ser de Portugal, cujo arauto é o próprio Pessoa. Bernardo Soares dá uma pista dessa fundação: "a única maneira de teres sensações novas é construíres-te uma alma nova.” (PESSOA, 1999, p. 284). 
Para dar cabo a esse projeto, Pessoa precisou se multiplicar. Os heterônimos “instalam originariamente a contigência do múltiplo" (BADIOU, 2002, p.63). Nesse processo de se outrar ele diz "nunca me sentindo tão portuguesmente eu, senão como quando me sinto diferente de mim - Alberto Caeiro, Ricardo Reis, Álvaro de Campos e Fernando Pessoa, e quantos mais haja havidos ou por haver" (PESSOA, 1966, p.94). Sua ambição de universalidade é indicada na cosmovisões geradas pelos heterônimos e são produzidas pelo sonho, faculdade essencial sobre a qual diz Bernardo Soares:

Nesta era metálica dos bárbaros só um culto metodicamente excessivo das nossas faculdades de sonhar, de analisar e de atrair pode servir de salvaguarda à nossa personalidade, para que se não desfaça ou para nula ou para idêntica às outras. (PESSOA, 1999, pp. 333-4).

O sonho promove uma abertura ao Ser, escondido numa "cotidianidade enxovalhante", e é o que dá acesso ao poetar.

Conforme Bernardo Soares, para a salvaguarda da personalidade, deve-se cultivar o sonho, a análise e atração. Por sonho entendo a capacidade de abstração da realidade, e uma técnica com a finalidade não de fuga do real, mas de concebê-lo por uma via diferente:

As figuras dos sonhos não são para mim iguais às da vida. São paralelas. Cada vida - a dos sonhos e a do mundo - tem uma realidade igual e própria, mas diferente. Como as coisas próximas e as coisas remotas. (PESSOA, 1999, p. 126).

Como a realidade não pode ser apreendida, tudo para Pessoa é um vir a ser. O sonho é o que torna factível atingir toda realidade, é um sentir às avessas em que o sujeito se faz presente, na medida em que vira os olhos para dentro; o sonho faz passar o dentro para fora (GIL, s/d, p.139). No sentir propriamente dito, se dá o contrário, o Eu desaparece em detrimento do sensível, o Eu se torna todo exterior porque "na percepção, nós não pensamos o objeto e não nos pensamos pensando-o, nós somos para o objeto (...)" (MERLEAU-PONTY, 1999, p. 320).

A análise refere-se à decomposição do sentir, que ocorre no sonho, sendo na decomposição em que o mundo apresenta novas configurações. Atrair, no sentido de "trazer para si": trazer o mundo para si ao invés de lançar-se nele cegamente. Eis o que Soares indica. 
Apesar de Soares ser uma "mutilação" da personalidade de Pessoa, como este mesmo o confessa, é ele quem, a meu ver, provoca maior grau de inquietação pelo olhar oblíquo e ao mesmo tempo agudo. Sua "autobiografia sem fatos" mostra que basta olhar para o mundo obliquamente para ele transformar-se em outra coisa. No entanto, ainda olha-se o mundo, para além do visível:

Sonhar designa uma forma de acesso à realidade, que não provém da simples razão ou da percepção sensorial, mas da imaginação (re)criadora, que pergunta, não pelo que é mas pelo que poderia ser, deixando assim entrever as bases essenciais de uma realidade inatingível por outras vias. (MOISÉS, 1999, p. 81).

Desse modo, a inação é crucial. Somente o não agir permite o sonho. É no sonho que se atinge as esferas mais altas da vida. É no sonho que se vive mais plenamente a vida. É no sonho que se pode prescindir da técnica, por exemplo. É no sonho que o Homem pode se afirmar como Homem. Esse é um dos laços que une Heidegger e Fernando Pessoa, qual seja, a única ação geradora de mudança reside no pensar/sonhar. Não há verdadeiramente uma oposição entre esses dois termos, visto que o sonho concatena o sentir ao pensar. O pensar proposto pelo sonho não deixa de ser uma reflexão acerca do mundo circundante, onde novas significações brotam para além da banalidade cotidiana. $\mathrm{O}$ sonho representa as faculdades imaginativas e criadoras do homem. Soares comprova que não é preciso haver "fatos", "acontecimentos" no sentido corrente do termo, para que essas novas significações sejam engendradas. Talvez seja até mais profícuo o sonho porquanto nele o pensamento "dilata-se" de forma a abarcar toda a multiplicidade do sentir.

Pessoa poetiza o mundo e propõe ao leitor/espectador o mesmo. Afinal, como afirma Heidegger, "[é] a poesia que permite ao homem habitar sua essência" (HEIDEGGER, 1997, p. 178). Isso se dá a partir da linguagem. Esta "recolhe e transforma um mundo mais antigo, onde vivem leitor e escritor, entre ambos se instala a cumplicidade, (...), a fascinação e a diferença que permitirá um leitor tornar-se escritor" (CHAUÍ, 1994, p. 489).

A poesia não conduz o Homem para o reino da Fantasia, ao contrário. "Ela traz o homem para a terra, para ela, e assim o traz para um habitar" (HEIDEGGER, 1997, p. 169). No entanto, esse habitar só é possível onde a palavra poética dá a medida. O poeta 
escuta o apelo da linguagem, ela é o apelo mais primordial, segundo Heidegger. É ela que nos acena as essências das coisas. Não se quer dizer que a linguagem nos disponibiliza uma verdade das coisas, como se a coisa tivesse uma verdade. A linguagem desvela o Ser das coisas, elas passam a existir na linguagem. No entanto, na linguagem cotidiana, as coisas velam-se, pois a técnica fez com que olhássemos o mundo pelo viés do uso, da disponibilidade - o mundo é aquilo que está disponível para nós, para que dele desfrutemos. É no dizer poético que as coisas se desvelam, o mundo mostra-se. Esse mundo

como demonstra Heidegger, não é nem uma reunião de objetos, nem uma espécie de recipiente que os contenha, e sim um espaço livre de possibilidades, o espaço de sentido e de relações que um povo abre com suas escolhas essenciais, suas decisões em relação à vida/à morte, ao verdadeiro/ao falso, ao humano/ao divino, etc. (HAAR, 2000, pp. 85-6).

Poder-se-ia pensar que, contudo, há um afastamento da realidade devido à apologia do sonho. Ao contrário, o sonho não afasta da vida, mas faz imergir num nível muito mais profundo dela. A inação não significa apenas ter uma atitude contemplativa frente à vida, e sim um modo possível para o sonho, para viver a vida em toda sua plenitude. Dado o processo intelectual exigido para tal, é compreensível o cansaço do poeta: "O que tenho sobretudo é cansaço, e aquele desassossego que é gémeo do cansaço quando este não tem outra razão de ser senão o estar sendo.” (PESSOA, 1999, p. 312).

Não obstante o cansaço, Pessoa nos convoca a uma travessia pelas coisas através da poesia a fim de descobrir novas significações. Promove um rompimento abrupto da vida cotidiana, ao mesmo tempo em que o poeta não se desliga completamente da mesma, nem poderia.

\section{BIBLIOGRAFIA:}

BADIOU, Alain. Pequeno Manual de Inestética (trad. de Marina Appenzeller). São Paulo: Estação Liberdade, 2002.

CHAUÍ, Marilena de Souza. Merleau-Ponty : Obra de arte e filosofia, In : VVAA. Artepensamento. São Paulo: Companhia das Letras, 1994, p. 467-492 
GIL, José. Fernando Pessoa ou a Metafísica das sensações. Lisboa : Relógio d’Água, $\mathrm{s} / \mathrm{d}$

HAAR, Michel. A obra de arte: ensaio sobre a ontologia das obras. (trad. Maria Helena Kühner). Rio de Janeiro : Difel, 2000.

HEIDEGGER, Martin. Ensaios e conferências. (Trad. Emmanuel Carneiro Leão et alli) Petrópolis : Vozes, 1997

Hölderlin et l'essence de la poésie (trad. de Henry Corbin).In : Approche de Hölderlin. Paris : Gallimard, 1973.

. Serenidade. (Trad. Maria Madalena Andrade e Olga Santos) Lisboa : Instituto Piaget, 2000.

LOURENÇO, Eduardo. Da literatura como interpretação de Portugal. In: O labirinto da saudade. 2a Ed. Lisboa: Dom Quixote, 1982.

MACHEREY, Pierre. À quoi pense la littérature? Paris : PUF, 1990.

MERLEAU-PONTY, Maurice. Fenomenologia da Percepção. (Trad. Carlos Alberto R. de Moura). São Paulo, Martins Fontes, 1999.

MOISÉS, Carlos Felipe. Os poemas e as máscaras. Florianópolis : Letras Contemporâneas, 1999.

OSAKABE, Haquira. Fernando Pessoa : resposta à decadência. Curitiba : Criar, 2002. PAZ, Octávio. El desconocido de sí mismo : Fernando Pessoa. In: Los signos en rotación y otros ensayos. Madrid: Alianza Tres, 1983, p. 105-128.

PERRONE-MOISÉS, Leyla. Fernando Pessoa : aquém do eu, além do outro. São Paulo : Martins Fontes, 2001.

PESSOA, Fernando. Livro do Desassossego. São Paulo : Companhia das Letras, 1999. . Obras em prosa. Rio de Janeiro : Nova Aguilar, 1974. . Páginas Íntimas e de Auto-Interpretação. Lisboa: Ática, 1966. . Sobre Portugal - Introdução ao problema nacional (introdução e org. de Joel Serrão). Lisboa : Ática, 1978. 